\title{
MINERALIZAREA ȘI RAPORTUL ÎNTRE IONII PRINCIPALI ÎN APELE RÂULUI PRUT
}

\author{
Nina Bagrin, Elena Zubcov \\ Institutul de Zoologie, e-mail: boichenco_nina@mail.ru
}

https://doi.org/10.53937/9789975151979.03

\begin{abstract}
Rezumat
Lucrarea include rezultatele cercetării mineralizării și raportului între ionii de hidrocarbonaţi și carbonați- $\mathrm{HCO}_{3}^{-}+\mathrm{CO}_{3}^{-}$, sulfaţi-SO ${ }_{4}^{-}$, cloruri- $\mathrm{Cl}$, calciu - $\mathrm{Ca}^{2+}$, magneziu - $\mathrm{Mg}^{2+}$, sodiu - $\mathrm{Na}^{+}$și potasiu - $\mathrm{K}^{+}$, în apele r. Prut în aval de acumularea Costești-Stînca (Braniște, Sculeni, Leușeni, Cahul, Cîșlița Prut, Giurgiulești) în anul 2020.
\end{abstract}

Cuvinte-cheie: ioni principali, mineralizare, raport între ioni, calitatea apei, râul Prut.

\section{INTRODUCERE}

Anionii de hidrocarbonați și carbonați, sulfați, cloruri și cationii de calciu, magneziu, sodiu și potasiu reprezintă componentele structurale ale compoziției chimice și calității apei. Cantitatea și raportul dintre aceste componente determină salinitatea, gustul apelor naturale, fiind determinatoare și în estimarea funcționării ecosistemelor acvatice și proceselor care se petrec în bazinele hidrografice ale acestor ecosisteme.

Cantitatea si calitatea apelor dulci a devenit o problemă vitală pentru planeta Terra. Fără descifrarea proceselor care se petrec în mediul acvatic, stabilirea echilibrului și toleranței resurselor acvatice la provocările tehnogene și schimbările globale climaterice este imposibilă valorificarea durabilă a acestor resurse de importanță vitală cum sunt resursele de apă. Un monitoring simplu al conținutului unor componente chimice în apele ecosistemelor acvatice este insuficient, fiind necesară și descifrarea proceselor privind funcționarea acestor ecosisteme.

Lucrarea dată este o încercare de a demonstra care este situația actuală în dinamica componentelor structurale ale componenței chimice în apele r.Prut în anul curent plin de extreme - de la secetă hidrologică pînă la inundații puternice și invers.

Este bine cunoscut că mineralizarea apelor dulci curgătoare, cît și conținutul ionilor principali este într-o dependență funcțională de parametrii fizico-geografici îndeosebi de volumul și regimul

\begin{abstract}
The paper includes the results of mineralization research and the ratio of hydrogen carbonate and carbonate ions $-\mathrm{HCO}_{3}^{-}+\mathrm{CO}_{3}^{-}$, sulphates $-\mathrm{SO}_{4}^{-}$, chlorides - $\mathrm{Cl}$, calcium - $\mathrm{Ca}^{2+}$, magnesium - $\mathrm{Mg}^{2+}$, sodium $-\mathrm{Na}^{+}$and potassium $-\mathrm{K}^{+}$, in the waters of the Prut River downstream of Costesti-Stinca reservoir (Braniste, Sculeni, Leuseni, Cahul, Cislita Prut, Giurgiulești) in 2020.
\end{abstract}

Keywords: main ions, mineralization, ion ratios, water quality, Prut River.

scurgerii apelor, caracteristica si caracterul precipitaților atmosferice, regimul termic, componența rocilor muntoase, solurilor și apelor subterane, schimbările reliefului bazinului hidrografic, dar și de factorii tehnogeni - de exemplu barajarea și îndiguirea râurilor, deversarea apelor reziduale, diminuarea zonelor de protecție și pădurilor, utilizarea irațională a resurselor acvatice și agrochimicatelor.

\section{MATERIALE ȘI METODE}

Eșantioanele de apă au fost colectate pe porțiune râului Prut de la Braniște pînă la Giurgiulești în anul 2020, în timp de iarnă (februarie), cînd temperatura aerului a fost destul de înaltă, iar nivelul apei - caracteristic pentru etiaj, primăvara (mai), care s-a caracterizat printr-un nivel, la fel, scăzut al apei, vara (iunie-iulie), în perioada inundațiilor, și toamna (octombrie) după o secetă, fără precedent, de 4 luni.

Colectarea și prelucrarea probelor hidrochimice a fost efectuată conform standardelor ISO adaptate la cele naționale [1-2]. Investigațiile de laborator au fost efectuate prin metode titrimetrice $\mathrm{cu}$ utilizarea biuretelor automate Pellet și digitale Solarus, metode gravimetrice și emisie atomică prin utilizarea spectrometrului ICP OES de emisie cu plasmă cuplată inductiv ICAP 6000. Datele obținute au fost prelucrate prin programele Statistica-10 și Excel-10. 


\section{REZULTATE ȘI DISCUȚII}

Valorile mineralizării apelor r. Prut au oscilat anul curent în limitele 281-292 mg/l în perioada ploilor abundente din iunie-iulie și 590-604 mg/l în februarie în perioada nivelului calciului, ceea ce înseamnă că în ele predomină anionii sporite pentru luna februarie. Anul 2020 să deosebește prin perioada îndelungată de etiaj în februarie-martie, ploi abundente în iunie-iulie, și secetă hidrologică extremă în iulie-octombrie. Aceste salturi de temperaturi sporite cît și caracteristica specifică a precipitaților abundente din 2020 au provocat un diapazon de c-ca $400 \mathrm{mg} / \mathrm{l}$ între perioada de etiaj și cea de viituri în dinamica mineralizării apelor r.Prut. Pe cursul râului mineralizarea crește treptat în diapazonul 50-150 mg/l, cu maxime în timpul etiajului. Însă valorile mineralizării în anul 2020 sunt mai scăzute decât cele care au fost în anii 2009-2011 [3].

Este cunoscut faptul că dinamica mineralizării și a ionilor principali, în majoritatea cazurilor, de- pinde de factorii naturali, dar schimbarea raportului între diferiți cationi si anioni poate fi deseori influențat de factorului uman, mai corect - tehnogen.

Apele r. Prut se referă la cele hidrogenocarbonate, grupa calciului, ceea ce înseamnă că în ele predomină anionii de carbonați și cationii de calciu. Pentru aprecierea raportului între cationi și anioni în apele investigate, au fost calculați coeficienții de corelație luând în calcul concentrațiile în $\mathrm{mg} / \mathrm{l}$ și în mmol/l. Rezultatele demonstrează o corelație evidentă între anionii și cationii principali, dar observăm o corelație între cationii de calciu și carbonați mai mică decît între ionii de calciu și clorurile și mai mică decît intre anionii de carbonați cu cationii de magneziu, sodiu și potasiu. La fel, cationii de potasiu sunt intr-o corelație mai mare cu anionii de carbonați și sulfați decât cu cei de cloruri (Tabelul 1). Aceste abateri mici pot fi argumentate prin condițiile specifice pentru anul curent de la etiaj în iarnă-primăvară - până la inundație- și invers secetă (etiaj extrem).

Tabelul 1. Corelația între anionii și cationii principali în apele r. Prut.

\begin{tabular}{|l|c|c|c|c|c|c|c|}
\hline & $\mathrm{HCO}_{3}{ }^{-} \mathrm{CO}_{3}^{-}$ & $\mathrm{SO}_{4}{ }^{2-}$ & $\mathrm{Cl}^{-}$ & $\mathrm{Ca}^{2+}$ & $\mathrm{Mg}^{2+}$ & $\mathrm{Na}^{+}$ & $\mathrm{K}^{+}$ \\
\hline $\mathrm{HCO}_{3}{ }^{-}+\mathrm{CO}_{3}^{-}$ & $\mathbf{1 , 0 0}$ & 0,91 & 0,85 & 0,75 & 0,88 & 0,91 & 0,88 \\
\hline $\mathrm{SO}_{4}{ }^{--}$ & 0,91 & $\mathbf{1 , 0 0}$ & 0,86 & 0,67 & 0,87 & 0,94 & 0,80 \\
\hline $\mathrm{Cl}^{-}$ & 0,85 & 0,86 & $\mathbf{1 , 0 0}$ & 0,82 & 0,88 & 0,96 & 0,75 \\
\hline $\mathrm{Ca}^{2+}$ & 0,75 & 0,67 & 0,82 & $\mathbf{1 , 0 0}$ & 0,89 & 0,81 & 0,75 \\
\hline $\mathrm{Mg}^{2+}$ & 0,88 & 0,87 & 0,88 & 0,89 & $\mathbf{1 , 0 0}$ & 0,96 & 0,92 \\
\hline $\mathrm{Na}^{+}$ & 0,91 & 0,94 & 0,96 & 0,81 & 0,96 & $\mathbf{1 , 0 0}$ & 0,87 \\
\hline $\mathrm{K}^{+}$ & 0,88 & 0,80 & 0,75 & 0,75 & 0,92 & 0,87 & $\mathbf{1 , 0 0}$ \\
\hline
\end{tabular}

Este clar că dinamica mineralizării apei r.Prut este determinată de conținutul ionilor principali. În timpul perioadei de studiu, concentrațiile calciului au fluctuat între 48,1 și 78,2 mg/l, magneziului - între 8,5 și $23,1 \mathrm{mg} / \mathrm{l}$, sodiului - între 8,3 și $62,8 \mathrm{mg} / \mathrm{l}$, și potasiului - între 4,5 și $11,2 \mathrm{mg} / \mathrm{l}$, sulfaților - între 38,3 și 137,0 mg/l, clorurilor între 14,0 și $45,9 \mathrm{mg} / \mathrm{l}$, hidrocarbonaților - între 156 și 256 mg/l (Fig.1,2).

Între valorile mineralizării și ionilor principali la fel există o dependență vizibilă (Tabelul 2, Figurile. 3,4).

Tabelul 2. Corelația între concentrația anionilor, cationilor principali și mineralizarea apei r. Prut în 2020.

\begin{tabular}{|l|c|c|c|c|c|c|c|}
\hline & $\mathrm{HCO}_{3}{ }^{+}+\mathrm{CO}_{3}^{-}$ & $\mathrm{SO}_{4}{ }^{2-}$ & $\mathrm{Cl}^{-}$ & $\mathrm{Ca}^{2+}$ & $\mathrm{Mg}^{2+}$ & $\mathrm{Na}^{+}$ & $\mathrm{K}^{+}$ \\
\hline Mineralizarea & 0,97 & 0,97 & 0,91 & 0,76 & 0,91 & 0,96 & 0,86 \\
\hline
\end{tabular}




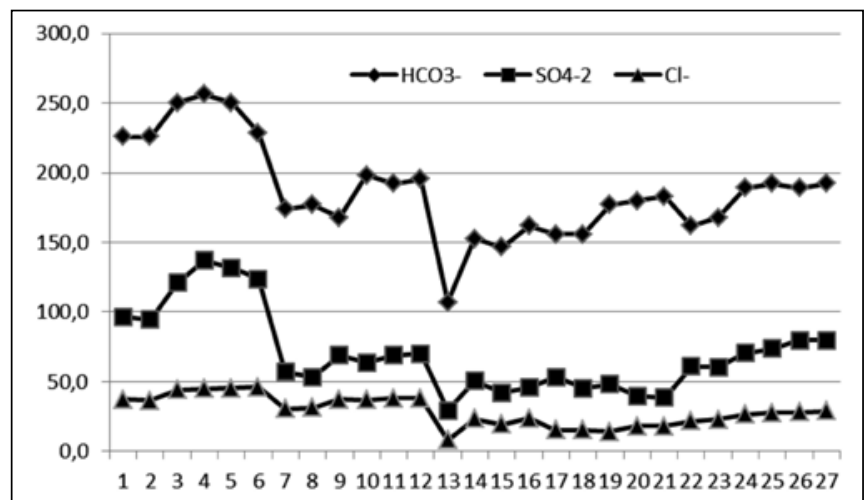

Fig. 1. Dinamica anionilor de hidrocarbonați și carbonați- $\mathrm{HCO}_{3}^{-}+\mathrm{CO}_{3}^{-}$, sulfați- $\mathrm{SO}_{4}^{-}$, cloruri-Cl, în apele r.Prut, anul 2020, mg/l.

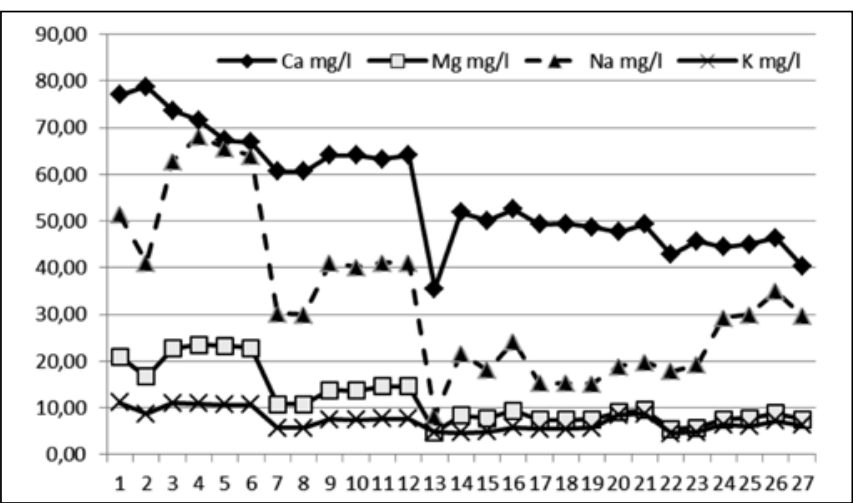

Fig. 2. Dinamica cationilor de calciu - $\mathrm{Ca}^{2+}$, magneziu $\mathrm{Mg}^{2+}$, sodiu $-\mathrm{Na}^{+}$și potasiu $-\mathrm{K}^{+}$, în apele r.Prut, anul 2020, mg/l.
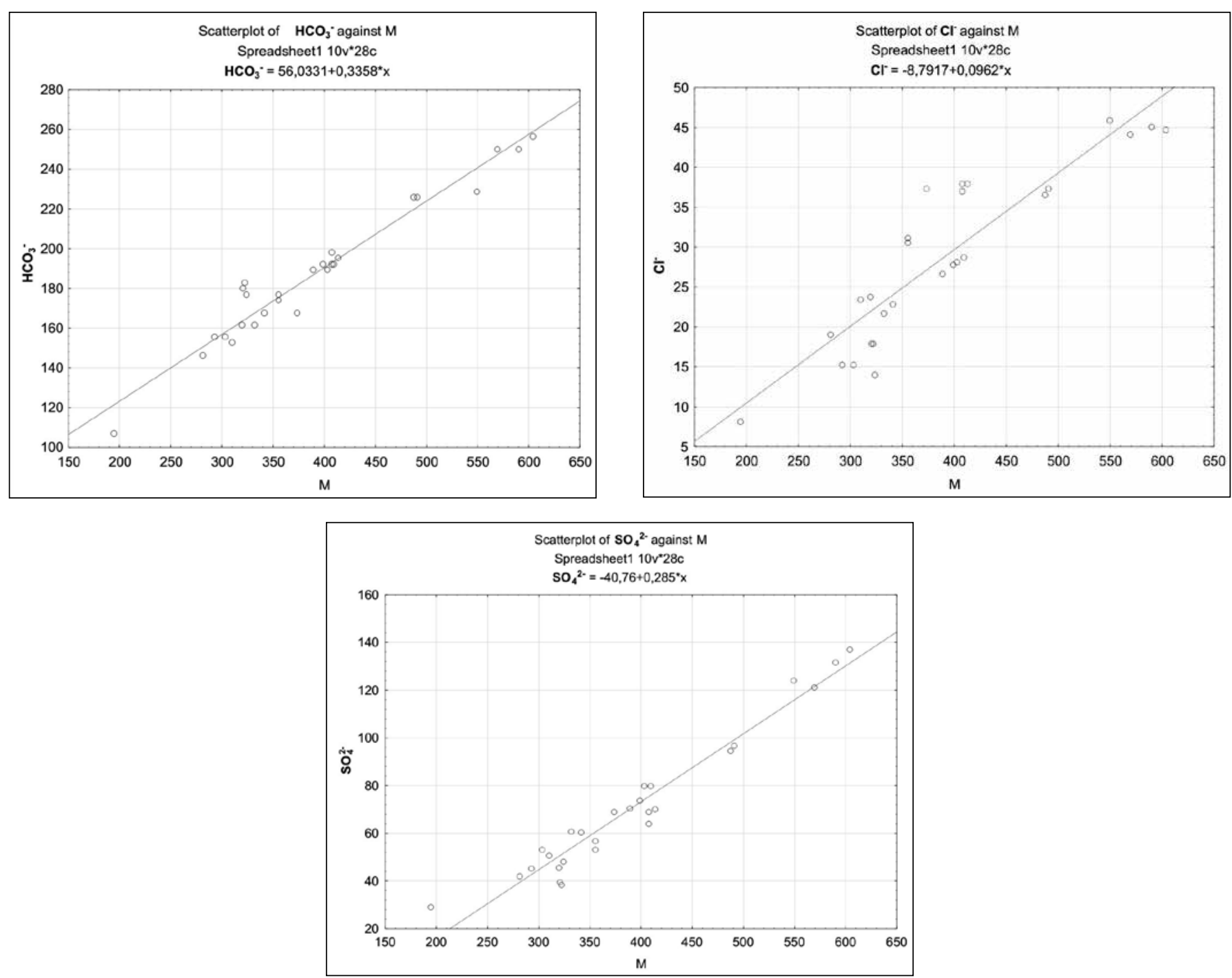

Fig. 3. Dependența între conținutul anionilor de hidrocarbonați și carbonați $\mathrm{HCO}_{3}^{-}$, sulfați - $\mathrm{SO}_{4}^{-}$, cloruri - $\mathrm{Cl}^{-}$și valorile mineralizării apei în r.Prut, anul 2020. 

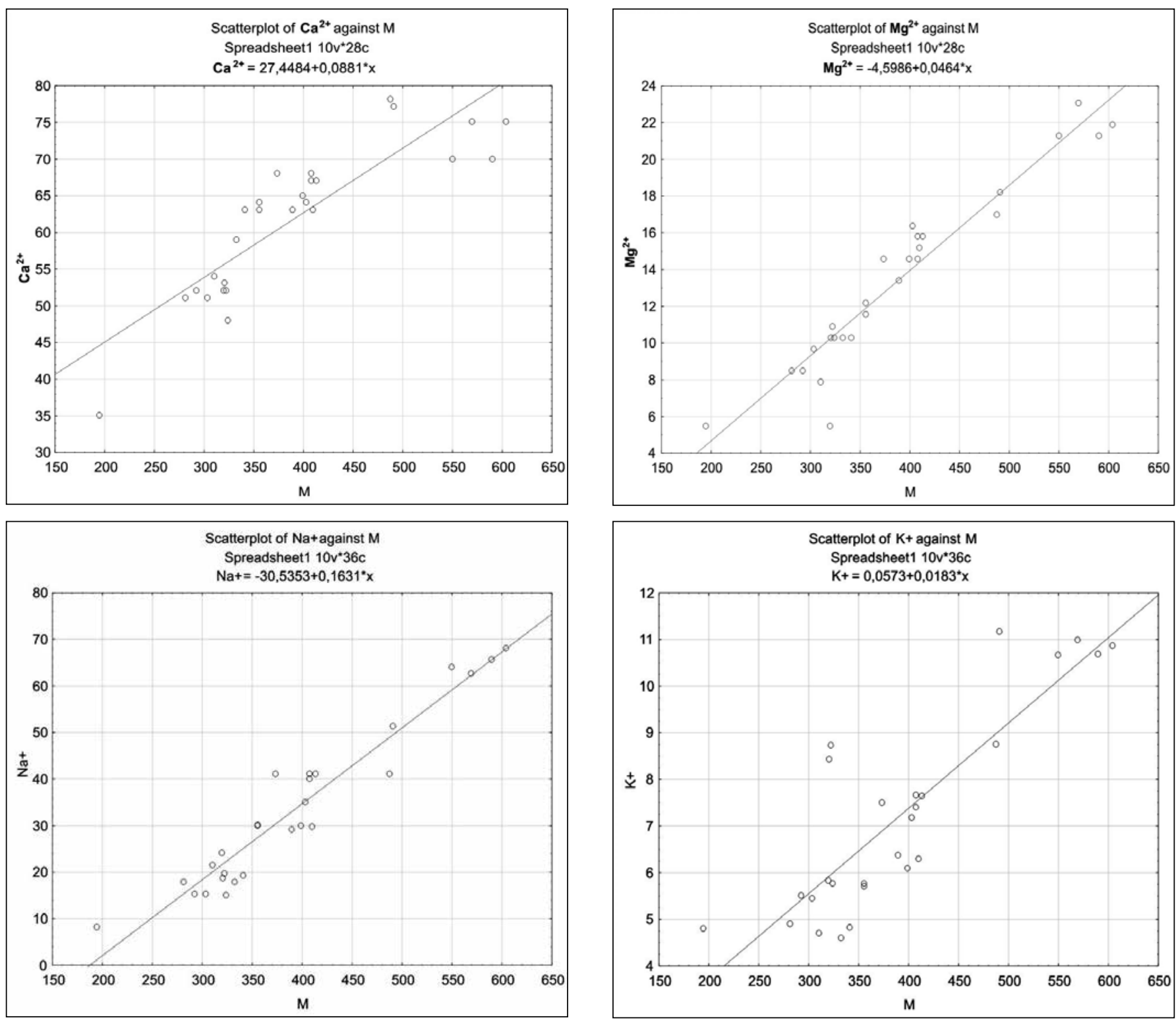

Fig. 4. Dependența conținutului cationilor de calciu, magneziu, sodiului, potasiu de valorile mineralizării apei în r.Prut, anul 2020.

\section{CONCLUZII}

Apele rîului Prut în anul curent conform Regulamentului cu privire la cerințele de calitate a mediului pentru apele de suprafață [4], reieșind din dinamica conținutul ionilor principali și a mineralizării în majoritatea cazurilor corespund clasei I de calitate (foarte bună), cu excepția lunii februarie, când apele au fost de clasa II de calitate (bună).

Investigațiile sunt realizate în cadrul proiectului 20.80009.7007.06 "Determinarea schimbărilor mediului acvatic, evaluarea migrației și impactului poluanților, stabilirea legităților funcționării hidrobiocenozelor și prevenirea consecințelor nefaste asupra ecosistemelor (Programul de Stat 2020-2023) și a proiectelor BSB 27 și BSB 165 finanțate de Uniunea Europeană (Programul Operațional Comun "Bazinul Mării Negre 2014-2020”).

\section{REFERINTTE}

1. SM SR ISO 5667-4:2007 Calitatea apei. Prelevare. Partea 4: Ghid de prelevare a apelor din lacuri naturale şi artificiale

2. Monitoringul calității apei și evaluarea stării ecologice a ecosistemelor acvatice. Indrumar metodic., Chișinău: Elan poligraf, 2015. 80 p.

3. Zubcov, E., Ungureanu, L., Toderaș, I., Bagrin, $N$. Hydrobiocenosis State of the Prut River in the Sculeni - Giurgulesti Sector. Water Science and Technology Library. Management of Water Quality in Moldova. Springer, 2014, Volume 69 p. 97-156.

4. Regulamentului cu privire la cerințele de calitate a mediului pentru apele de suprafață . Hotărîre Guvernului RM, nr. 890 din 12.11.2013. Monitorul Oficial Nr. 262-267 art. Nr : 1006 din 22.11.2013 